\title{
EL SUSTRATO IDEOLÓGICO Y POLÍTICO DE LA CRÍTICA DE MISES AL MONISMO METODOLÓGICO
}

\author{
Gustavo MARQUÉs \\ CIECE. Instituto de Investigaciones Administrativas \\ FCE. Universidad de Buenos Aires
}

RESUMEN. El propósito de este trabajo es mostrar las razones que subyacen a la crírica de Mises al monismo metodológico y a la concepción popperiana de la ciencia. Dichas razones conciernen a la viabilidad y aceptabilidad del Estado de Bienestar y de las políticas económicas y sociales que éste pudiera implementar, la factibilidad del régimen socialista, las perspectivas del capitalismo y el destino mismo de la civilización occidental. Para Mises, el debate epistemológico estaba supeditado a consideraciones económicas y políticas. En última instancia, puede decirse que Mises creía que en el debate metodológico estaba en juego la dirección del cambio social: o la humanidad continuaba elevando los estándares de vida que habían sido posibles en Europa sólo merced al mercado, o se emprendía un penoso regreso a la época de las cavernas. Ello explica la crudeza de sus argumentos y la intransigencia con que defendía sus opiniones.

ABSTRACT. The aim of this paper is to analyze the Misesian objections to methodological monism and the Popperian idea of science. It is shown that these objections mostly relate to the viability and ethical acceptability of both the Welfare State and the socialist regimes. For Mises, the real issue at stake in the methodological debate was the future of Western societies, and that is why his arguments were so fierce. The alternative was either to keep the markets rising our standards of living or to fall again into our darkest past. 


\section{Introducción}

Es sabido que Popper y Hayek mantuvieron una relación amistosa en lo personal y de coincidencia y de colaboración en lo intelectual. Son numerosas las citas cruzadas, siempre aprobatorias del pensamiento del otro. Tan estrecha es la relación entre ambas visiones, que Caldwell ha procurado, merced a su acceso a los archivos epistolares de Hayek, abiertos luego de su muerte, dilucidar quién ha sido influyente sobre el pensamiento epistemológico de quién ${ }^{1}$. Menos tratada y menos clara es la relación entre Popper y von Mises. Revisando la obra de Popper no se encuentra casi referencia a la obra de aquél. Por su parte, Mises no hace alusión alguna a Popper en su monumental Human Action (1949) y sólo lo menciona en contadas ocasiones en su obra tardía. Es extraño porque el pensamiento de Mises coincide en gran medida con las ideas defendidas en La Sociedad Abierta y sus Enemigos y en Miseria del Historicismo, y sus enemigos eran prácticamente los mismos: Bacon, Comte, el utopismo en todas sus formas, desde luego Hegel y Marx, y doctrinas como el historicismo y el colectivismo. Ambos eran liberales y defendían los valores del individualismo, el mercado y la democracia.

En el terreno epistemológico, en cambio, los desacuerdos explícitos, en el caso de las ciencias sociales, eran sustanciales. Sorprende, sin embargo, que las actitudes respectivas ante estas discrepancias, sea marcadamente diferente. Popper, quien pensaba que el conocimiento sintético a priori era imposible, puede haber considerado que no valía la pena continuar discutiendo lo que ya había sido resuelto definitivamente. Ello explicaría su desinterés por el pensamiento misiano. Para Mises, en cambio, era imperioso continuar el debate metodológico. Esto puede explicarse, en parte, porque el "positivismo" era por ese entonces la visión dominante y la carga del esfuerzo discursivo recae sobre quien quiera modificar las relaciones de poder imperantes en materia metodológica. Sin embargo, las discrepancias metodológicas y epistemológicas per se, aunque existentes, no justifican la tenacidad y crudeza con que Mises atacó con todas las armas disponibles al monismo metodológico y a sus defensores.

El propósito de este trabajo es mostrar que para Mises existían otras razones, más profundas, de naturaleza económica, social y política, que constituyen el

1 Caldwell 2002. 
motivo central de su participación en la controversia. Dichas razones conciernen a la viabilidad y aceptabilidad del Estado de Bienestar y de las políticas económicas y sociales que éste pudiera implementar, la factibilidad del régimen socialista, las perspectivas del capitalismo y el destino mismo de la civilización occidental. Para Mises, el debate epistemológico estaba supeditado a consideraciones económicas y políticas. En última instancia, sin riesgo a exagerar, Mises creía que en el debate metodológico estaba en juego la dirección del cambio social: o la humanidad continuaba elevando los estándares de vida que habían sido posibles en Europa sólo merced al mercado, o se emprendía un penoso regreso a la época de las cavernas. Ello explica la crudeza de sus argumentos y la intransigencia con que defendía sus opiniones.

\section{La crítica de Mises al monismo metodológico}

Mises pasaba por alto los matices que separaban a Popper del círculo de Viena, y parecía incluirlo sin más en este movimiento ${ }^{2}$. Sin embargo, no presentaba objeciones a los puntos de vista expuestos en la Lógica de la investigación cientifica, y aprobaba sin reparos la metodología "falsacionista" para las ciencias naturales ${ }^{3}$. A decir verdad, consideraba que las ideas del empirismo a este respecto eran un lugar común, tan poco objetables como originales ${ }^{4}$. Sus diferen-

2 Aún hoy algunos representantes de la escuela Austriaca continúan incluyendo a Popper en el movimiento empirista lógico: "El "Círculo de Viena» fue organizado en 1924 por el filósofo Moritz Schlick (1882-1936) [...] El Círculo estaba compuesto por un grupo dedicado a —o interesado en- la filosofía positivista, que sostenía que sólo la percepción sensorial era una base permisible de conocimiento y de pensamiento preciso.. Entre sus miembros prominentes estaban Rudolf Carnap, Kurt Gödel, Felix Kaufmann, Carl Menger, Jr., Otto Neurath, y Karl Popper» (Ebeling 2000: 148). Desde luego, Popper mismo hubiera rechazado enérgicamente esta adscripción. De hecho, la mayor parte de sus escritos epistemológicos apuntan, directa o indirectamente, a marcar sus diferencias con el "positivismo lógico" y a ofrecer una alternativa al mismo. Pero, desde la óptica radicalmente opuesta de Mises, estas diferencias debieron parecerle simples reyertas de familia que era conveniente pasar por alto para denunciar su núcleo común.

3 "[D]ebemos enfatizar que el error del positivismo no reside en lo que enseña acerca de los métodos de las ciencias naturales empíricas [...] El principio positivista de verificabilidad, tal como ha sido rectificado por Popper, es incuestionable en cuanto principio epistemologico de las ciencias naturalesn (Mises 1962: cap. 7.3; subrayado por Mises).

4 «En la medida en que el principio empiricista del positivismo lógico refiere a los métodos experimentales de las ciencias naturales, meramente afirma lo que no es cuestionado por nadie» (Mises 1962: cap. 8.5). 
cias epistemológicas con Popper surgían exclusivamente en referencia a las ciencias humanas (sociales).

En efecto, Popper había defendido el monismo metodológico en múltiples ocasiones y, en Miseria del Historicismo hace un esfuerzo por conciliar esta postura con la concepción de Hayek ${ }^{5}$. Es natural que Mises le atribuyera la pretensión de prescribir el «método experimental» también para las ciencias de la acción humana. Su objeción era que este método sólo era apto para la física y demás ciencias naturales ${ }^{6}$. Precisamente, "lo que asigna a la economía su posición única y peculiar, en la órbita del conocimiento puro y de la utilización práctica del conocimiento, es el hecho de que sus teoremas particulares no son susceptibles de ninguna verificación o falsación sobre la base de la experiencia» (Mises 1996a: 858; subrayado por $\mathrm{mi})$. Sus razones en defensa de esta postura resultan ser ahora más actuales que entonces.

En primer lugar, la exigencia empirista de testar las teorías es inaplicable en economía, pues la evidencia histórica es compleja y cada quién puede interpretar en ella lo que desee o necesite ${ }^{7}$. Por ello, aunque Mises pensaba que la teoría económica había demostrado de manera concluyente el carácter perjudicial de

5 Véase el parágrafo 29 de Miseria del Historicismo, en donde Popper se esfuerza por mostrar que, bien entendida, la posición aparentemente dualista de Hayek (quien señala lo que juzga son diferencias importantes entre el método de la economía y el método de las ciencias físicas) resulta compatible con el monismo metodológico.

"Al describir el "método experimental" que atribuye al positivismo, Mises señala que "es obvio que todo esto no puede concernir de ninguna manera a los problemas de las ciencias de la acción humana. No hay en esta esfera tal cosa como hechos establecidos experimentalmente. Debe repetirse una y otra vez que toda experiencia en este campo es experiencia histórica, es decir, experiencia de fenómenos complejos. Semejante experiencia nunca puede producir algo que tenga el carácter lógico de lo que las ciencias naturales llaman uhechos de experienciam" (Mises 1962: cap. 4.8).

7 "[A] esto se debe la embarazosa situación que se presenta cuando defensores de doctrinas incompatibles apelan a la mismos datos históricos como evidencia de su corrección. La afirmación de que las estadísticas pueden probar cualquier cosa es el reconocimiento popular de esta verdad. Ningún programa político o económico, no importa cuán absurdo sea, puede ser contradicho por la experiencia a los ojos de sus defensores. Quienquiera que esté convencido a priori de la corrección de su doctrina puede siempre señalar que no se han cumplido algunas de las condiciones esenciales para que su doctrina se muestre correcta. Cada uno de los partidos políticos alemanes busca en la experiencia del segundo Reich la confirmación de la sensatez de su programa. Defensores y opositores del socialismo extraen conclusiones opuestas a partir de la experiencia del bolchevismo ruso" (Mises 1996a: 864). 
las políticas intervencionistas, no creía posible refutar a sus defensores señalando el hecho (para él obvio) de que conducía a resultados exactamente opuestos de aquellos que se buscaban. Contra lo que pregonaba el "positivismo", las teorías económicas no eran verificables ni refutables empíricamente.

En segundo lugar, el positivismo concebía de manera equivocada los papeles respectivos de la razón y los sentidos. La experiencia, lejos de ser juez de las teorías, debia ser interpretada a la luz de éstas. Esto significaba que la importancia y validez de las enseñanzas económicas no sólo no podía ser determinada mediante la experiencia, sino que, por el contrario, era la teoría económica la que debía necesariamente usarse para iluminar los acontecimientos históricos. Los mismos hechos podían ser interpretados de diversas maneras, pero sólo la teoría económica permitía identificar cuál, de entre las diversas interpretaciones posibles, era la correcta ${ }^{8}$.

Se desprende de lo dicho, que para Mises las teorías económicas no podían ser evaluadas por sus consecuencias observacionales. La justificación de los teoremas económicos debla seguir la dirección opuesta a la sugerida por el empirismo moderno: no descendiendo hasta sus consecuencias, sino al revés: remontándose hacia sus premisas. Sin embargo, se presentaba aquí una dificultad lógica importante para quien deseaba —como los austríacos - defender la verdad objetiva de la teoría económica por medios exclusivamente racionales. La dificultad es la siguiente: no hay manera alguna de justificar deductivamente un teorema (consecuencia). La deducción sólo puede transmitir la verdad ya adquirida, pero no puede conferirla a la conclusión si no la posee previamente en sus premisas. Esta es la razón por la que Popper era antijustificacionista: ni la inducción (que rechazaba) ni la deducción (que aprobaba) podían ser usadas para probar teorías?. Por ello,

8 "En el ámbito del conocimiento praxeológico, ni el éxito ni el fracaso hablan un lenguaje preciso, audible a todo el mundo. La experiencia derivada exclusivamente de fenómenos complejos no impide incurrir en interpretaciones basadas en deseos. La ingenua propensión humana a adscribir omnipotencia a sus pensamientos, por confusos y contradictorios que sean, nunca es falsada por la experiencia de manera manifiesta e inambigüa. El economista nunca puede refutar las falacias económicas de la manera en que el doctor refuta al curandero y al charlatán. La historia babla solo a aquella gente que conoce cómo interpretarla sobre la base de las teorías correctas" (Mises 1996: 858-859; subrayado por $\mathrm{mi}$ ).

9 Y es por esta razón que David Miller sostiene la inexistencia de buenas razones. Véase Miller 1994: cap. 3. 
Mises necesitaba admitir el carácter sintético y válido a priori de las premisas de la teoría económica. En la medida en que esta propiedad puede serle atribuida, el axioma de la acción humana le proporcionaba el anclaje que necesitaba para intentar construir luego toda la teoría económica de manera enteramente deductiva ${ }^{10}$.

Los reparos epistemológicos de Mises, aunque importantes en sí mismos, indican la presencia de una diferencia más sustancial, de carácter político, entre ambos pensadores. $\mathrm{Y}$, a juzgar por sus declaraciones, resulta obvio que para Mises (en mayor medida que para Popper) se trataba mucho más que de una mera discusión académica acerca de los aspectos epistemológicos del conocimiento. Mises consideraba que el grupo de pensadores abroquelados en torno al Círculo de Viena, compartían una visión de la ciencia a la que atribuía consecuencias políticas desastrosas.

En la medida en que (el positivismo) rechaza los principios epistemológicos de las ciencias de la acción humana, no sólo está completamente equivocado. Está también socavando, consciente e intencionalmente, los fundamentos intelectuales de la civilización occidental. (Mises 1962: cap. 8.5)

Para el lector moderno, acostumbrado a las críticas del pensamiento popperiano procedentes del sector izquierdo del espectro político, es difícil dar crédito a estas acusaciones. Pero el hecho es que Mises veía un vínculo entre la visión de la ciencia de Popper y las fuerzas que se oponían al capitalismo y al mundo libre. Para Mises, el monismo metodológico no sólo era una concepción epistemológica errónea, sino que era políticamente peligrosa: era una doctrina anticapitalista, y un auxiliar del socialismo y el comunismo ${ }^{11}$.

${ }^{10}$ No proseguiremos esta discusión porque no es necesaria para nuestro trabajo. Sólo cabe mencionar que aunque es sencillo enunciar la estrategia que ha de seguirse, no es nada fácil llevarla a la práctica. Para ser exitoso, el apriorismo metodológico debe efectuar correctamente dos tareas: mostrar el carácter valido apriori de los axiomas de la teoría económica, y mostrar que las leyes y teoremas que han sido obtenidos mediante el trabajo mancomunado de clásicos y subjetivistas pueden ser adecuadamente deducidos de dichos axiomas. Usualmente, la discusión se ha centrado en el primer punto, pero el segundo es igualmente esencial y, por cierto, no es menos espinoso que el primero.

11 "[...] Otto Neurath insufló al monismo metodológico de la "ciencia unificada" su nota definidamente anticapitalista, y convirtió al neopositivismo en un auxiliar del socialismo y el comunismon (Mises 1962: cap. 8.4). 
Es más, avizoraba una operación de pinzas sobre el libre mercado, una especie de división conspirativa del trabajo intelectual. De una parte, el mercado era vapuleado por las ideologías más burdas y utópicas, dirigidas a ganar el corazón de las masas incultas; de otra, la ideología refinada del positivismo apuntaba a conquistar, con argumentos, la sobria razón de la intelectualidad. Eran dos discursos diferentes, destinados a diferentes audiencias, pero que convergían hacia el mismo objetivo ${ }^{12}$. ¿Cuál es exactamente el nexo que Mises percibía entre la aplicación de la concepción empirista de evaluación de teorías a las ciencias sociales y la destrucción del orden de mercado?

Para responder esta pregunta, es necesario mostrar que junto a amplios acuerdos de todo tipo, políticos, económicos y sociales, a los que hicimos referencia en la Introducción, existían significativas diferencias entre ambos pensadores acerca del papel del conocimiento científico, los mecanismos político institucionales y el sistema de libre mercado. Estas discrepancias podrán parecer menores para el juicio corriente, pero no para Mises. Ponerlas de manifiesto nos permitirá apreciar mejor qué se halla en juego tras las divergencias metodológicas.

\section{El papel de la ciencia natural, la ciencia social y el mercado}

Popper asignaba una importancia singular al conocimiento científico y al método que lo hacía posible. Consideraba que el conocimiento que hemos adquirido como especie era uno de los hechos más trascendentes de nuestra historia y lo que nos distinguía más nítidamente del resto de los animales. Más aún, veía en el crecimiento constante del conocimiento uno de los hechos más trascendentes de la historia de la vida sobre el planeta Tierra ${ }^{13}$. En este sentido, resulta-

12 «Hoy en día, ambas doctrinas, el polilogismo marxiano y el positivismo, compiten amigablemente el uno con el otro prestándole apoyo teórico a la «izquierda». Para los filósofos, matemáticos y biólogos, está la esotérica doctrina del positivismo lógico o empirico, en tanto que las masas menos sofisticadas son alimentadas mediante un confusa variedad de materialismo dialécticon (Mises 1962: cap. 8.4).

13 "El conocimiento, y su crecimiento, ha tenido más y más influencia sobre la vida de los hombres, tanto directamente, como por medio de sus aplicaciones tecnológicas [...]. Pero si miramos hacia atrás desde nuestra posición privilegiada actual, podemos decir, creo, no sólo que es en nuestro conocimiento donde diferimos más claramente de los otros animales, sino que [...] podemos ver el crecimiento de nuestro conocimiento no sólo como el principal patrón de la historia humana, sino quizá también de la evolución de la vida” (Popper 1996: 133). 
ba comparable con otros hitos memorables, como el surgimiento de las islas coralinas y la producción de oxígeno a partir de las plantas ${ }^{14}$.

La adquisición y desarrollo del conocimiento, no ha sido fruto de la casualidad. En numerosas ocasiones Popper ha sostenido que el conocimiento (y su acumulación) no hubieran sido posibles sin el empleo sistemático del método crítico, consistente en arriesgar conjeturas y procurar refutaciones. El método científico moderno no es más que una versión algo más sofisticada de este procedimiento. Es muy probable que, dentro de ciertos límites, el propio Mises hubiese compartido el entusiasmo popperiano por la ciencia y su método. La diferencia está en los énfasis y en las consecuencias y asociaciones que comportan. Para Popper, la ciencia y el método crítico tenían una importancia que trascendía el ámbito estrictamente gnoseológico y se proyectaba al nivel social y político. Es con este espíritu que remarcaba el "poder liberador de la ciencia" (Popper 1996: 105), sostenía que «la tarea cultural de la ciencia es contribuir a la autoliberación por medio del conocimiento" (Popper 1996: 109) y describía el método crítico como «lo que nos ha hecho ser lo que somos, y lo que nos ofrece la esperanza de continuar nuestra autoemancipación a través del conocimienton (Popper 1996:61).

La función social y emancipadora que Popper asignaba al conocimiento y al método científico hacía que, sorpresivamente, compusiera alianzas circunstanciales con autores que, en otros aspectos, se encontraban en las antípodas de su pensamiento (y que habían sido criticados por él de manera sistemática y severa). Bacon, a quien ha vapuleado en innumerables ocasiones, es considerado "el padre espiritual de la ciencia moderna», y elogiado por haber anticipado ( $y$ contribuido) al advenimiento de "una sociedad cientifica e industrial —una sociedad basada en el dominio del hombre sobre la naturaleza. La promesa de Bacon es la promesa de autoliberación del hombre por medio del conocimienton" ${ }^{15}$.

14 «Sugiero que el hombre ha creado una nueva clase de producto o artefacto que promete hacer cambios tan grandes en nuestro rincón del mundo como los realizados por nuestros predecesores, las plantas productoras de oxfgeno, o los corales constructores de islas. Estos nuevos productos, que son tan claramente fruto de nuestra elaboración, son nuestros mitos, nuestras ideas y, especialmente, nuestras teorías científicas" (Popper 1996: 134).

15 "A pesar de todo lo que he dicho, Bacon es el padre espiritual de la ciencia moderna. No a causa de su filosofía de la ciencia y de su teoría de la inducción, sino porque se ha convertido en el fundador y profeta de una iglesia racionalista - una especie de anti-iglesia. Esta iglesia fue fundada no sobre una roca, sino sobre una visión, y en la promesa de una sociedad cientifica e industrial 
Estas declaraciones no debieran tomarnos por sorpresa, pues, como ha dejado en claro en su Introducción a Conjeturas y refutaciones, lo que más valoraba Popper del racionalismo y empirismo clásicos es haber difundido el optimismo gnoseológico y preparado el camino de una nueva era de autoafirmación por medio del empleo de la propia razón y los propios sentidos. Sorprende, en cambio, su inesperado reconocimiento de Marx, quien uestá comprometido, como nosotros, con la idea de autoemancipación a través del conocimiento - a través del crecimiento de la ciencia» (Popper 1996: 109).

Aunque Mises compartía en buena medida la actitud positiva de Popper ante el conocimiento, resulta impensable hallar en sus obras expresiones entusiastas equivalentes. Mises libraba una guerra contra el cientismo, y debió haber advertido que buena parte de su prestigio provenía del culto positivista a la ciencia natural. Por ello, aunque valoraba el conocimiento científico, no le atribuía el mérito de haber dado origen al mundo moderno, ni veía en la ciencia (y mucho menos en sus aplicaciones ingenieriles) el gran motor del desarrollo de la humanidad. Para él, la llave para la autoemancipación de la humanidad se encontraba enteramente en el mercado. La división del trabajo, la cooperación y, sobre todo, el circuito virtuoso conformado por el ahorro, la acumulación y la inversión, constituyen los hitos decisivos, que han permitido al hombre elevarse desde la primitiva sociedad de castas a las sociedades democráticas modernas, en las que los individuos gozan de un nivel de vida sin precedentes en la historia de la humanidad. Lo central era el sistema económico y social, no el conocimiento científico o el poder que éste nos otorga sobre el mundo natural.

Mises y Popper diferían también en el sentido de la conexión causal que pueda establecerse entre conocimiento científico y mercado. Mises no aceptaba que la aplicación del conocimiento científico y su método hayan generado el orden de mercado. Este no ha sido fruto de la autoemancipación humana, entendida como un desarrollo consciente y deliberado. Como han sostenido más explícitamente Menger y Hayek, el orden de mercado se ha generado de manera espontánea (es fruto de nuestras acciones, pero no de nuestros designios). En mayor medida aún, Mises descartaba la pretensión cientista, que atribuía al aumento de nuestro conocimiento la capacidad de mejorar el funcionamiento del mercado.

- una sociedad basada en el dominio del hombre sobre la naturaleza. La promesa de Bacon es la promesa de autoliberación de la humanidad por medio del conocimienton (Popper 1996: 195-196). 
Desde el punto de vista misiano existía un vínculo entre la fascinación con la ciencia, el incremento del conocimiento y la fe en su potencia emancipadora, de una parte, y el papel transformador (y liberador) atribuido a las políticas sociales y al diseño institucional, de la otra. En una palabra, percibía un vínculo entre el culto a la ciencia y lo que Hayek (1981) denominó "racionalismo constructivista».

Sin embargo - sostenía—, el (auténtico) vínculo causal es exactamente inverso: es el mercado, una vez instalado, quien ha posibilitado el desarrollo y aprovechamiento del conocimiento científico, el mejoramiento generalizado de las condiciones de vida y, en definitiva, la misma civilización occidental. Para Mises, la autoemancipación del hombre (es decir, su elevamiento sustancial por encima de las condiciones de vida animal y pretérita), así como el desarrollo del conocimiento y todas sus aplicaciones tecnológicas, eran, en última instancia, consecuencias (no causas) del laissez faire.

El rasgo característico de la moderna civilización occidental no reside en sus descubrimientos científicos y su utilidad para el mejoramiento de los estándares de vida de la gente y la prolongación de la duración media de vida. Estos son meramente los efectos del establecimiento de un orden social en el cual, debido a la instrumentación de un sistema de beneficios y pérdidas, los más eminentes miembros de la sociedad son promovidos para servir con lo mejor de sus habilidades el bienestar de la masa de gente menos dotada. (Mises 1962: cap. 8.3)

Por ello, el gran actor de su drama no es el científico, sino el empresario. Pero, sobre todo, lo que debe valorarse es el sistema, que le permite a éste desarrollar sus destrezas en bien de todos. Desde esta perspectiva, si de conocimientos se trata, por encima del científico natural, Mises resaltaba la contribución de aquellos economistas, que han descubierto el "gran principio" de funcionamiento del mercado, dilucidando la importancia central de la división del trabajo, la asociación y la cooperación. Aunque, desde antaño, la humanidad advirtió sus ventajas en la práctica, ello no se reflejó de inmediato al nivel de la teoría. Por el contrario, hubo quienes negaron su conveniencia (como el mercantilismo) o su misma existencia (como el marxismo). Por ello, para Mises era de vital importancia reconocer el enorme mérito de los economistas clásicos, quienes aportaron el conocimiento del mecanismo y las consecuencias económicas y sociales del mercado. La humanidad no debe perder ni el orden de mercado, ni la teoría acerca del mismo. Ambas contribuciones son fundamentales. 


\section{Leyes y normas: el papel de la política y de lo económico}

Un punto de acuerdo importante entre Popper y Mises es que ambos defendían la existencia de leyes sociales y económicas. Pero parecen diferir en la manera de concebirlas y en la posibilidad (y deseabilidad) de suplementarlas mediante normas e instituciones adecuadas. Los resultados sorprendentes de la física moderna impactaron en un mundo dominado por la visión animista de la naturaleza y mostraron que ésta estaba sujeta a leyes inexorables independientes de la voluntad humana. En los asuntos sociales, en cambio, continuó reconociéndose el primado del capricho y el humor de los gobernantes. Uno de los méritos que Mises reconocía a la filosofía social del Iluminismo es haber socavado esta creencia y mostrado que «todo poder es limitado en sus efectos por el hecho de que todos los fenómenos sociales responden a leyes» (Mises 2003: 212).

Estas declaraciones deben ser tomadas al pie de la letra. En su esfuerzo por desalentar los proyectos utópicos y voluntaristas a escala social, Mises no establecía ninguna diferencia entre las leyes naturales y sociales.

Cuando hablamos de las leyes de la naturaleza, tenemos en mente el hecho de que allí prevalece una inexorable interconexión de fenómenos físicos y biológicos, y que el hombre que actúa debe someterse a esta regularidad si desea tener éxito. Cuando hablamos de las leyes de la acción humana nos referimos al hecho de que tal inexarable interconexión de fenómenos está también presente en el ámbito de la acción humana en cuanto tal y que el hombre que actuia debe reconocer también esta regularidad si desea tener éxito (Mises 1996a: 755; subrayado por mí).

Del mismo modo en que no se puede violar las leyes de la naturaleza, Mises creía que quienes osaban desafiar a las leyes del mercado se enfrentaban a la misma imposibilidad. Las leyes praxeológicas son «independientes del capricho humano, son hechos ontológicos primarios que restringen rígidamente el poder del hombre para actuar" (Mises 1996a.: 756). Por ello, desconocer las leyes imperantes en el mercado conducía inexorablemente al fracaso.

Por otra parte, aunque pudiéramos torcer dichas leyes, nuestra intervención no sería necesaria, porque cuando se permite al mercado funcionar sin trabas "prevalece una irresistible tendencia a emplear cada factor de producción para la mejor satisfacción posible de las necesidades más urgentes de los consumidores» 
(Mises 1996a: 736). Es, en verdad, una contingencia afortunada que nuestra sociedad esté investida de leyes inevitables que convergen al bien común.

Popper manifestaba una postura mucho más cauta acerca de las bondades del sistema y la inevitabilidad de sus leyes. Aunque deseaba defender el libre mercado y la sociedad democrática, admitía que librado a sí mismo, el capitalismo ha conducido a excesos inaceptables, y en tanto persista esta situación "seguirá siendo posible que una minoría económicamente fuerte explote a la mayoría de los económicamente débiles" (Popper 1992: 306). Por otra parte, sin desconocer la existencia de leyes sociales (o económicas), ponía un énfasis considerable en la existencia de normas e instituciones que conformarían el entramado de restricciones propiamente social. Las instituciones constituyen restricciones porque imponen límites y funcionan como obstáculos a nuestras acciones, pero no se imponen a ellas con total inexorabilidad. Este énfasis en el aspecto institucional le hace sostener que es posible y necesario implementar políticas sociales que permitan mantener el mercado (con todas sus consecuencias ventajosas) y, al mismo tiempo, eliminar sus excesos. En un tono que suena keynesiano sostenía que:

[E]l poder político es fundamental y puede controlar al poder económico [...] Podemos preguntarnos qué deseamos lograr y cómo lograrlo: podemos, por ejemplo desarrollar un programa político racional para la protección de los económicamente débiles; podemos sancionar leyes para restringir la explotación; podemos limitar la jornada de trabajo; y si bien todo esto no es despreciable, podemos hacer mucho más. Mediante las leyes, podemos asegurar a los trabajadores (o mejor aún, a todos los ciudadanos) contra la incapacidad, la desocupación y la vejez. De esta manera, haremos imposibles aquellas formas de explotación basadas en la desvalida posición económica de un trabajador que debe aceptar cualquier cosa para no morirse de hambre. Y cuando podamos garantizar por ley un nivel de vida digno a todos aquellos que estén dispuestos a trabajar - y no hay ninguna razón para que esto no se logre-, entonces la protección de la libertad del ciudadano contra el temor y la intimidación económicos será casi perfecto. Desde este punto de vista, el poder político constituye la llave de la protección económica. El poder político y su control lo es todo. No debemos permitir que el poder económico domine al político; y si es necesario, deberá combatírselo hasta ponerlo bajo el control del poder político. (Popper 1992: 307) 
Es difícil señalar en este párrafo siquiera una línea que Mises hubiese aprobado sin salvedades importantes. Respecto a las relaciones entre economía y politica, ambas perspectivas son exactamente opuestas. Como hemos señalado, Mises subrayaba (y hasta absolutizaba) el papel decisivo de las leyes económicas y las distinguía cuidadosamente de las normas (a las que designaba como «man-made moral precepts»). Las normas pueden ser sustituidas si son halladas inadecuadas, pero las leyes no pueden ser evitadas, y por ello deben ser sabiamente acompañadas. Es natural, por ende, que subestimara las posibilidades de la política. Esta es tanto más potente cuanto más desapercibida pasa (es decir, cuanto más se abstienen las autoridades de intervenir) y es por completo contraproducente cuando se manifiesta ostensiblemente.

El hecho de que el nivel de vida de un trabajador americano medio es incomparablemente más satisfactorio que el de un trabajador chino medio, que en los Estados unidos la jornada de trabajo es más corta y que los niños son enviados a la escuela y no a las fábricas, no es un logro del gobierno y de las leyes del pais. Es un resultado del hecho de que el capital invertido por número de empleados es mucho mayor que en China y que consecuentemente la productividad marginal del trabajo es mucho mayor. Esto no es el mérito de "políticas sociales"; es el resultado de los métodos de laissez faire implementados en el pasado, los cuales se abstuvieron de sabotear la evolución del capitalismo. (Mises 1996a: 740-741; subrayado por mí)

El motor del desarrollo (tanto en términos económicos, como sociales) era, según Mises, el ahorro, la acumulación y la inversión. Por ello, el buen gobierno debía limitarse a garantizar que se dieran las condiciones legales e institucionales para que la acumulación y la inversión tengan lugar. Lo que debía ser protegido no era el asalariado o el desempleado, sino la propiedad privada y la posibilidad de obtener beneficios por su intermedio, lo que automáticamente originaría acumulación e inversión ${ }^{16}$.

En suma, ambos aceptaban la existencia de un doble sistema de restricciones, conformado por leyes y normas (instituciones). Pero concebían la interac-

\footnotetext{
16 "Todo lo que puede hacer el buen gobierno para mejorar el bienestar material de las masas es establecer y preservar un conjunto de instituciones que no ponga obstáculos a la acumulación progresiva de nuevo capital y a su utilización para la mejora de los procedimientos técnicos de producción" (Mises 1996b:5).
} 
ción entre ambos sistemas de manera completamente diferente. Popper creía que normas adecuadas podían mejorar el desempeño de las leyes económicas y sociales. Mises, por el contrario, sostenía que esas normas sólo podían entorpecer y distorsionar su funcionamiento. Juzgaba que las políticas que por ese entonces se implementaban en Europa para resolver las alegadas imperfecciones del mercado, eran falaces, fruto de un arrebato voluntarista y completamente inefectivas. Eran falaces porque se fundaban en una incomprensión del funcionamiento del mercado (y de sus beneficios), y eran inefectivas porque el sistema capitalista está regido por leyes cuyas consecuencias era imposible evadir. Esto explica que el intervencionismo no alcanzara los resultados que se proponía.

\section{El desdichado destino del intervencionismo}

Mises no sólo rechazaba la regulación estatal del mercado, sino que poseía una teoría acerca de por qué era necesario oponerse al menor atisbo de intervencionismo. Hasta podría decirse que concebía a la teoría económica como el conjunto de razones por las que las autoridades no debían interferir con el funcionamiento espontáneo del mercado ${ }^{17}$. Exponiendo estas razones, se comprenderán con mayor claridad los reparos que oponía al pensamiento político y económico de Popper y, a posteriori, se apreciarán mejor las motivaciones de su crítica tenaz al monismo metodológico.

Una de las contribuciones decisivas de la escuela austríaca es la tesis de que las acciones de los individuos y, en particular, sus acciones económicas, están causadas (y deben ser explicadas) por sus expectativas y preferencias. Mises y Hayek han denominado subjetivismo a esta perspectiva. Su incorporación al análisis económico ha permitido sostener que los precios de mercado están determinados enteramente por los deseos y decisiones de los consumidores.

Como los empresarios adoptan decisiones sobre la base de los precios relativos, en última instancia no harían más que seguir las "órdenes" de aquellos. Este resultado, que es conocido como la tesis de la soberanía del consumidor, proporcionó a Mises un argumento moral poderoso contra la intervención estatal o cor-

17 «[E]l objetivo último de la teoría económica es evaluar los argumentos basados en ideología acerca de la intervención en la economía de mercadon (Gunning 2000). 
porativa: toda injerencia de este tipo era indeseable porque distorsionaba la voluntad popular. Al imponer restricciones a la producción, o al modificar los precios relativos, las autoridades obligaban al empresariado a utilizar los recursos de un modo diferente al dispuesto libremente por los consumidores ( $\mathrm{y}$ a adoptar decisiones diferentes a las que ellos mismos hubieran adoptado de haber podido decidir libremente el uso de sus insumos). En la medida en que afectaba el consumo, el intervencionismo estatal era, en cualquiera de sus formas, una intromisión en la esfera privada o, al decir de Mises, en el "reino de la libertad».

Este argumento es importante para el liberal, quien desea sostener que ninguna autoridad debe obstruir la libre decisión individual. Sin embargo, podría objetarse a este planteo que, además de los fines individuales, hay necesidades colectivas, que es competencia (y deber) del Estado proteger. Y que es tarea suya arbitrar los medios para obtener estos resultados. Después de todo, el propio Menger parece haber aceptado la conveniencia del intervencionismo estatal en ciertas circunstancias ${ }^{18}$. Las metas del gobierno pueden ser de lo más variadas. Por ejemplo, beneficiar a determinados sectores, promover una mayor equidad social, una redistribución del ingreso juzgada más adecuada o un mayor ritmo de crecimiento económico. La injerencia estatal podría ser defendida si estos fines fueran aceptables y si las medidas adoptadas fueran adecuadas para la obtención de los mismos. En el párrafo anteriormente citado de La sociedad abierta y sus enemigos, Popper reclamaba al estado un protagonismo de este tipo.

Aunque Mises disintiera de las metas autopropuestas por el estado, no podía emplear la teoría económica para objetarlas, porque la teoría no discute acerca de fines. Necesitaba pues un argumento diferente, que consistió en lo siguiente: toda vez que la intervención estatal intenta "torcer» las leyes inexorables del mercado, no logra alcanzar los objetivos que se propone. El intervencionismo estatal, según Mises, proveía los ejemplos más interesantes de consecuencias no esperadas (y no deseadas) de las propias decisiones. El intervencionismo fracasaba en sus propios términos (es interesante advertir que esta forma de criticismo es lo que Popper ha llamado crítica interna de un sistema de ideas).

Una crítica asociada a la anterior, pero diferente, y que explica en gran medida la intransigencia característica de Mises, es que el intervencionismo se auto-

${ }^{18}$ Kirzner 1990. 
alimenta. Quienes desconociendo la lógica económica, pretenden modelar la vida social sobre la base de cualquier preconcepto (se trate de compromisos morales o (presunto) conocimiento "científico" de lo social), cometerán necesariamente errores (es decir, los medios elegidos no los acercarán a la obtención de los fines buscados, sino que los alejarán de dicha meta). Ante la evidencia del resultado adverso, intentarán corregirlo (con idéntica impericia) mediante más intervenciones, las que arrojarán nuevos errores, etc. Por esta razón, el intervencionismo es esencialmente inestable y, por asi decirlo, autodestructivo: la conclusión lógica de este proceso de (desdichadas) intervenciones sucesivas es la planificación total de la economía. El intervencionismo no puede ser concebido como un sistema alternativo a los dos sistemas polares opuestos (socialismo y laissez faire). No hay una vía intermedia entre ambos sistemas.

Mises tenía una interpretación muy diferente de los defectos del capitalismo mencionados por Popper en La sociedad abierta. En algunos casos, como la existencia de amplios bolsones de pobreza, consideraba que, aunque ello existía y era un hecho lamentable, no se debía en realidad al capitalismo (sin trabas), sino al «sabotaje» sistemático de que éste ha sido objeto por los grupos de poder y los malos gobiernos. Sólo puede elevarse el nivel de vida de las masas dejando que el «sistema de beneficios y pérdidas" funcione libremente. Respecto de otras presuntas falencias del capitalismo, como la existencia de desigualdades en el ingreso y las rentas, la interpretación misiana era que estos rasgos, lejos de ser un mal que debía ser erradicado, constituían características necesarias para el funcionamiento del sistema (lo cual las convertía ipso facto en deseables para todo defensor del mercado).

Los promulgadores de reformas sociales cometían pues un doble error. En ciertos casos, al desconocer la teoría económica, no comprendían que las características del capitalismo que se proponían eliminar (sobre la base de juicios éticos enteramente subjetivos) son esenciales para su funcionamiento y para la adquisición de un bienestar material que sólo el mercado puede proporcionar. En otros casos, establecían mal los nexos causales y atribuían al capitalismo responsabilidad por lacras sociales, que, en realidad, eran un resultado de su ausencia, no de su presencia.

No es fácil encontrar una frase que represente más fielmente la posición que Mises rechazaba y contra lo cual luchó encarnizadamente, que la siguiente: "el 
principio de no intervención, del sistema económico sin trabas, debe ser abandonado; si queremos la libertad de ser salvaguardados, entonces deberemos exigir que la política de la libertad económica ilimitada sea sustituida por la intervención económica reguladora del estado. Deberemos exigir que el capitalismo sin trabas dé lugar al intervencionismo económico».

No fue pronunciada por un líder populista, ni un sindicalista rebelde, ni un militante socialista. Pertenece a La sociedad abierta y sus enemigos (Popper 1992: 306).

\section{El Estado de Bienestar y las dos vías al socialismo}

Aunque Popper defendía - quizás con salvedades- el Estado de Bienestar, rechazaba el comunismo y el socialismo, y se oponía a que aquél fuera identificado con éstos. Para Mises, en cambio, no había medias tintas, ni espacio para las distinciones sutiles. Sostenía que Marx había propuesto dos vías al socialismo: la gradual y la revolucionaria. La primera fue expresada en el Manifiesto Comunista y la segunda en El Capital. Creía que los marxistas y propulsores del socialismo no tenían una opinión unánime al respecto: algunos preferían la abolición violenta del sistema mediante un solo golpe, en tanto que otros promovian su destrucción paso por paso. Pero más allá de estas diferencias en cuanto a la estrategia, el objetivo común de todos los sectores denominados "progresistas" era exactamente el mismo - la abolición del mercado- y debían ser combatidos con idéntica energía ${ }^{19}$.

Su visión extrema de la historia hacía que sólo viera perversidad en los motivos e intenciones de quienes impulsaban medidas gradualistas y redistributivas de corte keynesiano. Las medidas intervencionistas propuestas serían promovidas, no por ignorancia de sus consecuencias, sino a sabiendas de que generaban desempleo y depresión. Es más, cref́a que eran propuestas precisamente por ese motivo. El objetivo de los "progresistas» serfa generar aquellas condiciones recomendadas en el Manifiesto para socavar el sistema. Por ello, no prestaban aten-

19 «El antagonismo actual entre los comunistas, de una parte, y los socialistas, los New Dealers, y los Keynesianos, de la otra, es una controversia acerca de los medios a que debe recurrirse para alcanzar el objetivo común a ambas facciones: el establecimiento de la planificación central completa y la total eliminación de la economía de mercado" (Mises 1996b: 93). 
ción a sus críticos liberales, quienes, razonablemente, les advertían que esas políticas del estado de bienestar conducían al desastre: no los escuchaban porque era eso precisamente lo que deseaban. Las medidas impulsadas por el estado de bienestar formarían parte de una estrategia, concebida de manera consciente y deliberada, para implantar el socialismo gradualmente. Así, por ejemplo, el plan de los promotores del New Deal seria «alcanzar, paso por paso, el estado de bienestar de planificación central. Para alcanzar su objetivo habían adoptado las políticas «insostenibles" que el Manifiesto Comunista había declarado un «instrumento inevitable para revolucionar por completo el modo de producción»» (Mises 1996b: 98).

Su postura representa magníficamente lo que Popper hubiera considerado una ilustración de su teoría conspirativa de la ignorancia ${ }^{20}$. Ello hace que Mises perciba el sello del autoritarismo en propuestas que cualquier otro hubiera considerado parte del normal intercambio de ideas entre individuos de espiritu democrático. Esta lectura paranoica de la economía y de la política explican dos episodios que revelan lo extremo de su pensamiento y su relativo aislamiento incluso en el seno de los ultraliberales.

El primero involucra de manera directa a Hayek. En The Constitution of Liberty, éste había sostenido que el Estado de Bienestar, a diferencia del socialismo, era compatible con la libertad individual. Mises, que, en general, manifiesta una actitud positiva ante la obra, encuentra "frustrante» esta parte del libro y lo sermonea predicando su tesis de las dos vías:

Lo que separa a los comunistas de los defensores del Estado de Bienestar no es el objetivo último de sus esfuerzos, sino los métodos por medio de los cuales desean alcanzar el objetivo común a ambos. Las diferencias de opinión que los divide es la misma que distingue al Marx de 1848 del Marx de 1867, el año de la primer publicación del primer volumen de El Capital. En consecuencia, concluye, Hayek debiera saber que uel Estado de Bienestar es

${ }^{20}$ La teoría conspirativa de la ignorancia es una doctrina filosófica que presupone que la verdad es manifiesta para todo aquél que desea alcanzarlo y, en consecuencia, interpreta el disenso (el error) «no como una mera falta de conocimiento, sino como la obra de algún poder malévolo, fuente de influencias impuras y perniciosas que pervierten o envenenan nuestras mentes e instilan en nosotros el hábito de la resistencia al conocimiento" (Popper 1967: 10). 
meramente un método para transformar paso a paso la economía de mercado en socialismo. (Mises 1996b: 210-211)

El segundo episodio tuvo lugar en la primera reunión de la Asociación Mont Pelerin, en abril de 1947. Hayek había logrado reunir un importante número de destacados intelectuales, todos ellos liberales y simpatizantes del mercado. Allí estaban, entre otros, W. Eucken, L. Robbins, M. Polanyi, M. Friedman, H Hazlitt, W. Röpke, F. H. Knight, G. J. Stigler, M. Allais, K. Popper y F. Machlup (además de von Mises y el propio Hayek).

Según relata Friedman, en un momento, «estábamos discutiendo la distribución del ingreso, y si se podía tener impuestos progresivos al ingreso. Alguna de la gente allí reunida estaba expresando la opinión de que podría haber una justificación para ello». Fue entonces que Mises se paró y dijo «You're all a bunch of socialists", $y$ salió dando un portazo» ${ }^{21}$.

\section{El papel político del monismo metodológico}

Hemos expuesto separadamente las razones de Mises contra el monismo metodológico, y sus argumentos contra el diseño institucional, las reformas políticas y el intervencionismo estatal. Pero no hemos aclarado todavía qué vinculo percibe entre la propuesta de sociedad encarnada en el Estado de Bienestar y las ideas metodológicas y epistemológicas del empirismo moderno. Más específicamente, no hemos considerado todavía qué papel le asigna al monismo metodológico en la concepción y puesta en práctica de esas medidas.

Veremos ahora, que, en su paranoia, Mises llegó a creer que los "progresistas", término con el que designaba a todos los enemigos del mercado, asignaban a la epistemología "positivista" un papel fundamental que cumplir en su estrategia de implementación gradual del socialismo. En su visión, el monismo metodológico desempeñaba su papel de tres maneras diferentes: a) descalificando el tipo de investigación teórica que se necesita en economía; b) distrayendo recursos de la investigación que se necesitaba y reasignándolo a investigaciones de apo-

21 Véase "Milton Friedman reminisces about his career as an economist and his lifetime "avocation" as a spokesman for freedom», Entrevista de Brian Doherty, Reason Online, junio 1995. 
yo de las prácticas intervencionistas; $c$ ) deformando el pensamiento de la clase dirigente y restando apoyo popular a las medidas de política económica que era imprescindible realizar. Ya nos hemos referido al primer punto en la sección 1, por lo que aquí nos limitaremos a analizar los dos siguientes.

Siguiendo a Lenin, Althusser sostuvo que la filosofía era un arma de la revolución. La posición de Mises era idéntica en este punto. No debe perderse de vista que Mises estaba convencido de que todo lo expuesto - la superioridad y resultados benéficos del mercado y la libre cooperación, así como el carácter reaccionario del intervencionismo- había sido demostrado apodicticamente por la teoría económica. Al punto que todos los argumentos tebricos esgrimidos en su contra habían fracasado. Por esta razón, los únicos argumentos que los críticos del mercado atinaban a esgrimir eran aquellos que les proporcionaba la moderna visión empirista de la ciencia.

Los neopositivistas, ha declarado, "son conducidos por un aborrecimiento idiosincrático de la economía de mercado y sus corolarios políticos: gobierno representativo, libertad de pensamiento, de palabra y de prensa. Ellos luchan por el totalitarismo, la dictadura y la brutal opresión de los disidentes[...]. Sabiendo que no pueden avanzar ningún argumento razonable en contra de la critica de los economistas a sus planes, estos apasionados comunistas tratan de desacreditar la economia mediante argumentos epistemologicos" (Mises 1985: 242-43; subrayado por $\mathrm{m} i)$.

En su particular visión de la historia, las discusiones epistemológicas que referimos al comienzo, eran sólo parte de un juego político más amplio. Si el positivismo ha exigido que se teste a las teorías mediante la experiencia, descalificado la justificación exclusivamente racional de las teorías fácticas y negado la existencia de juicios sintéticos válidos a priori, se debió a que sus defensores percibían que ésta es la única manera de silenciar las enseñanzas de la teoría económica y estimular la elaboración de teorías alternativas en su lugar.

Este proyecto ya estaba en marcha y adoptaba diversas formas. Una de las consecuencias más palpables de la adopción del positivismo era el abandono de la (auténtica) teoría económica y su sustitución por lo que Mises califica como «historia económica». Durante la posguerra se han formado en los EEUU nume- 
rosos Institutos de Investigación destinados a promover la economía, copiando el modelo de los laboratorios de investigación en ciencias naturales ${ }^{22}$.

Esta orientación pasa por alto la diferencia metodológica fundamental entre las ciencias de la acción humana y las ciencias naturales. De hecho, no es posible experimentar en economía y el tipo de experiencia a que se enfrenta el economista es radicalmente diferente a la experiencia de laboratorio. En consecuencia, las investigaciones económicas empíricas se limitan a recoger datos del pasado. En realidad, lo que hacen es "tratar de sustituir el análisis económico por una colección a-sistemática de información histórica y estadística” (Mises 1996a: 870). No hacen teoría económica, sino historia económica. Y no captan el conjunto de relaciones económicas, sino sólo un aspecto (superficial) del mismo.

Mises no se opone a los estudios históricos, pero como cree que la teoría posee prioridad lógica por sobre la historia, no se puede hacer historia sin una buena base teórica que permita interpretar los hechos. "Las fundaciones de institutos para la investigación del cáncer, posiblemente puedan contribuir al descubrimiento de un método para combatir y prevenir esta perniciosa enfermedad. Pero un instituto para la investigación del ciclo de negocios no ayuda en nada a evitar la recurrencia de las depresiones. La más exacta y confiable compaginación de todos los datos concernientes a las depresiones económicas del pasado es de escasa utilidad para nuestro conocimiento de este campo. Los académicos no discrepan respecto de esos datos; discrepan acerca de los teoremas a que debe recurrirse para su interpretación" (Mises 1996a: 864; subrayado por mí). Escaso valor tienen, pues, los resultados de los cazadores de correlaciones empíricas.

Una segunda variante de análisis económico orientado a la experiencia consiste en especializarse en un sector o aspecto de la economía, como ser, economía laboral, economía agraria, intercambio regional, etc. Esta departamentalización de la economía no permite comprender las relaciones económicas. «Los problemas catalácticos no se tornan visibles si uno trata separadamente a cada

22 «El positivismo - sostiene- livianamente desestimó por completo el pensamiento histórico y económico. La historia, desde su óptica, simplemente no es ciencia; la economía es una clase especial de metafísica. En sustitución de ambos, el positivismo postuló una ciencia social que ha de ser construida mediante el método experimental tal como fue idealmente aplicado en la física newtoniana. La teoría económica tiene que ser experimental y cuantitariva» (Mises 1997: 93). 
rama de la economía" (Mises 1996a: 870). Más importante todavía es que esta manera de hacer economía no logra sustraerse al lobby de los diversos grupos de presión. El economista especializado en una rama particular termina expresando las ideas y las aspiraciones de grupos de poder vinculados a la misma.

En definitiva, trabajen para el gobierno, autoridades regionales o grupos de presión particulares, estas formas de economía aplicada no son otra cosa que herramientas para llevar adelante el proyecto intervencionista. $\mathrm{O}$, más precisamente, los diversos proyectos intervencionistas que cada sector - político o económico- desearía ver concretado en la práctica. En esto consiste el profesionalismo ${ }^{23}$. Diferentes grupos de expertos tratan de fundamentar y hacer viable las políticas que necesitan los grupos particulares que representan. Ninguno atiende al bien general.

Junto a la economía empírica que acabamos de describir, existe otra manea de hacer economía, de carácter mas bien formal y matemática, pero que se complementa bien con aquella. De hecho, esta alianza ha sido fructífera en ciencias naturales. La posibilidad de expresar las ideas en forma matemática ha permitido a las ciencias dar gigantescos pasos adelante, y obtener predicciones cuantitativas que son la base de diseños tecnológicos de amplísimas aplicaciones. Pero es crucial entender qué es lo que posibilita en este caso el empleo exitoso de las matemáticas. Estas «son significativas en la ciencia natural [...] porque la física es capaz de descubrir relaciones empiricas constantes, que describe mediante sus ecuaciones" (Mises 2003: 128; subrayado por mí).

El hallazgo de constantes es la clave para combinar de un modo óptimo la formulación matemática y la investigación empírica y estadística. De hecho, en ciencias naturales, "la formulación de una ecuación tiene importancia práctica porque las relaciones constantes que incluye están establecidas experimentalmente y porque es posible introducir en la función valores específicos conocidos para determinar los desconocidos" (Mises 1997: 96). Habiendo constantes, el

${ }^{23}$ «El desarrollo de una profesión de economistas es un subproducto del intervencionismo. El economista profesional es el especialista que cumple un papel instrumental, diseñando diversas formas de interferencia gubernamental con los negocios [...] Hay miles y miles de tales expertos profesionales ocupados en las oficinas de los gobiernos, de los diversos partidos políticos y de los grupos de presión" (Mises 1996a: 865). 
número de variables presentes en las ecuaciones disminuye y se vuelve posible lo que Hayek llamaba una ciencia de la simplicidad ${ }^{24}$. Es por esta razón que se procura copiar en economía la misma fórmula que ha resultado exitosa en física. Las mediciones econométricas estarían destinadas a llenar con valores concretos los parámetros de las ecuaciones de la economía matemática. La diferencia crucial es que en economía no hay constantes, y es por ello que las ecuaciones son aquí desprovistas de toda utilidad práctica.

En eso consistía la nueva economía que practicaban los economistas: cuantitativa y empírica, como lo exigían los criterios metodológicos de moda. Esa economía profesional estaba bien en términos de la epistemología prevaleciente, pero estaba mal en términos "ontológicos", ya que su objeto es intratable mediante esos procedimientos. La queja de Mises revela el carácter marginal de la escuela Austríaca, algo que se ha acentuado enormemente en el lapso que transcurre desde fines de los años 40 a la fecha.

\section{Los intelectuales y el papel de las masas}

Junto a la economía profesional, estaba la «economía» que relataban y transmitían quienes no eran economistas. Mises lamentaba que una pléyade de científicos sociales, políticos y formadores de opinión, inculcara ideas adversas al libre mercado y propiciara con impunidad la implementación de políticas intervencionistas. Era ésta la influencia más temida, porque la receptividad de sus ideas entre las masas era incomparablemente mayor que la obtenida por los economistas profesionales.

Las generaciones modernas contaban con la doble fortuna de vivir en una economía de mercado y de disponer de la teoría correcta que la explica y permite aprovechar las posibilidades que aquella ofrece. Para usufructuar esta circunstancia sólo faltaba una cosa: que los líderes implementaran políticas sensatas, sugeridas por la teoría económica, y que las masas apoyaran decididamente estas políticas. Nada de esto estaba ocurriendo, pero no debía atribuirse al hombre corriente la responsabilidad del fracaso. Consistente con el marcado elitismo que expresan sus escritos, Mises creía que "precisamente porque no son creativas y no desarrollan sus propias filosofias, (las masas) siguen a los líderes. Las ideologías

${ }^{24}$ Hayek 1967a. 
que produjeron todos los perjuicios y catástrofes de nuestro siglo no son un logro del vulgo. Son el logro de pseudo-académicos y pseudo-intelectuales. Estas ideas fueron propagadas desde las sillas de las universidades y desde el púlpito, fueron diseminadas por la prensa, por las novelas, el cine y la radio. Los intelectuales convirtieron a las masas al socialismo y al intervencionismo. Estas ideologías deben su poder al hecho de que los medios de comunicación han caído en manos de quienes las defienden, y a que casi todos los disidentes han sido virtualmente silenciados. Lo que se necesita para cambiar el curso es cambiar la mentalidad de los intelectuales. Luego las masas los seguirán”. (Mises 1996b: 175).

No es fácil ofrecer una interpretación de su pensamiento acerca de este punto en que el sentido común se sienta a sus anchas. Al parecer, Mises creía que la gente apoyaria las medidas que el laissez faire recomendaba, si las comprendiera adecuadamente. Incluso si - como es de prever- resultaran perjudiciales en el corto plazo. El problema residía, según él, en que desconocían las verdades inexorables que la teoría económica ha revelado; y ello era así, porque nadie, excepto un puñado de economistas e intelectuales liberales, se preocupaba por inculcárselas. No era tarea de la gente identificar y aprender a apreciar las correctas políticas económicas, sino de la intelectualidad, la cual debía transmitir estos conocimientos. Es ésta la que está fracasando, disipando con esta actitud irresponsable el capital acumulado por las generaciones anteriores y poniéndonos frente al riesgo de un retorno gradual a la época de las cavernas.

\section{Conclusión}

Mises creía que la teoría económica había ya mostrado de manera definitiva los resortes esenciales del mecanismo del mercado (sus leyes inexorables) e identificado las políticas económicas necesarias y sensatas. Sin embargo, los enemigos del capitalismo rechazaban los resultados de la teoría económica, pese a no contar con argumentos teóricos atendibles en su contra. ¿Qué es entonces lo que mantenía vigente esa actitud de rechazo? Naturalmente, existian motivos psicológicos y políticos para ello ${ }^{25}$. Pero éstos no podían ser reconocidos como tales. Se requería racionalizar el rechazo y para ello hacían falta argumentos. En ausen-

${ }^{25}$ Mises dedica el capítulo seis de Epistemological Problems of Economics a examinar «las bases psicológicas de la oposición a la teoría económica", entre las que menciona "los sentimientos de envidia y rencor" que el éxito empresarial genera "en los círculos de las clases educadas". En defi- 
cia de argumentos teóricos, quizás pudieran ser utilizados con éxito argumentos metateóricos. De hecho, Mises pensaba que los únicos argumentos que atinaban a esgrimir los opositores al capitalismo eran epistemológicos y provenían de la moderna metodología empirista, a la cual Popper habría proporcionado su versión más refinada. Bajo su influjo, el "positivismo" se había erigido en la metodología dominante y, consecuentemente, en árbitro de qué era científico y qué no lo era, contribuyendo a que prevaleciera un tipo de práctica económica asistencial e intervencionista que ponía en riesgo el futuro de la humanidad. Nada de esto era casual, según Mises. El positivismo no había llegado a jugar este papel merced a una contingencia histórica. Su visión conspirativa de la historia le hacía pensar que existía una estrategia deliberada de las fuerzas progresistas contra el mercado, en la cual la epistemología empirista moderna tenía un papel que desempeñar. Sus argumentos epistemológicos contra el positivismo son mejor comprendidos si se los concibe como parte de su cruzada contra las diversas formas de intervencionismo gradualista, que, según cree, responden a una estrategia cuyo fundamento se remonta al Manifiesto Comunista.

\section{Bibliografía}

CALDWEll, B., 1990, Carl Menger and his legacy in economics, Duke University Press, Durham y Londres.

—, 2002, "Popper and Hayek: Who Influenced Whom?», Ponencia presentada en el Karl Popper Centennary Congress (Viena, Julio 20002).

Ebeling, R. M. (ed) , 1997, Austrian Economics -A Reader, Hillsdale College Press, Hillsdale.

- (ed), 2000, Selected Writings of Ludwig von Mises, The Political economy of International Reform and Reconstruction, Liberty Fund, Indianapolis.

GunNing, J. P., 2000, "The Goal and Methods of Economic Theory», accesible en septiembre de $2004 \mathrm{n}$ la siguiente dirección:

http://www.constitution.org/pd/gunning/subjecti/mean_sub/gl_meth.pdf

nitiva, "Inferioridad subconsciente, complejos y envidia empujan a la gente hacia los partidos de izquierdan (Mises 2003: 176). En otros casos, como el de los adherentes a la Escuela Histórica Alemana, el rechazo de la teoría económica se debió a consideraciones eminentemente políticas: "uno combate a la economía porque no conoce otro medio de proteger un programa político insostenible contra las críticas desfavorables que emplean los hallazgos de la ciencia» (Mises 2003: lxxxi). 
HAYEK, F., 1937, «Economics and Knowledge», Economica, v. 4, pp. 33-54.

—, 1945, "The Use of Knowledge in Society", American Economic Review, v. 35, n. 4, pp. 519-530.

—, 1967a, "The Theory of Complex Phenomena", en sus Studies in Philosophy, Politics and Economics, Routledge \& Kegan Paul, Londres, pp. 22-42.

—, 1967b, «Degrees of Explanation», en sus Studies in Philosophy, Politics and Economics, Routledge \& Kegan Paul, Londres, pp. 3-21.

-, 1979, The Counter-Revolution of Science -Studies on the abuse of reason, Liberty Fund, Indianapolis. (Ed. Or.: 1953).

-, 1981, Nuevos estudios en filosofia, politica, economia e historia de las ideas, Eudeba, Buenos Aires. (Ed. Or.: 1978).

—, 1996 Individualism and Economic Order, The University of Chicago Press, Chicago y Londres.

KIRZNER, I., 1990, "Menger, classical liberalism, and the Austrian school of economics", en B. CALDWELL (ed), Carl Menger and his legacy in economics, Duke University Press, Durham y Londres, pp. 93-106.

Miller, D., 1994, Criticar Rationalism - A restatement and defense, Open Court, Illinois.

MISES, L. VON , 1962, The Ultimate Foundation of Economic Science, Mises Institute, on line.

—, 1985, Theory and History, L. von Mises Institute, Auburn. (Ed. Or. 1957).

—, 1996a, The Human Action, L. von Mises Institute, Auburn. (Ed. Or. 1949).

—, 1996b, Planning For Freedom, Libertarian Press, Grove City, Pennsylvania (Ed. Or. 1952).

—, 1997, "Social Science and Natural Science», en Ebeling, R. (ed), Austrian Economics -A Reader, Hillsdale College Press, Hillsdale, pp. 92-109.

—, 2003, Epistemological Problems of Economics, 3. edición, L. von Mises Institute, Auburn. (Ed. Or.: 1933).

Popper, K., 1967, El Desarrollo del Conocimiento Cientifico. Conjeturas y Refutaciones, Paidos, Buenos Aires. (Ed. Or.: 1963).

—, 1971, La lógica de la investigación cientifica, Tecnos, Madrid. (Ed. Or.: 1936). 
—, 1981, La miseria del historicismo, Alianza, Madrid. (Ed. Or.: 1944-45).

—, 1992, La Sociedad Abierta y sus Enemigos, Planeta-Agostini, Barcelona. (Ed. Or.: 1945).

—, 1996, The Myth of the Framework, Edición de M. A. Notturno, Routledge, LondresN. York. 